\title{
La disolución del soporte audiovisual y la quiebra de la linealidad en el relato
}

\author{
Robert ARNAU RoSELLó \\ Universitat Jaume I de Castelló \\ rarnau@uji.es \\ Esteban Galán CuBILlo \\ Universitat Jaume I de Castelló \\ egalan@uji.es
}

\section{Resumen}

En este momento de profundas transformaciones en el sector audiovisual, el recorrido realizado en el presente trabajo muestra cómo el siglo XX fue el de la aparición y consolidación de los medios de comunicación de masas (1.0) y el de la superación de sus limitaciones narrativas y de su unidireccionalidad. A finales del siglo XX y en los inicios del siglo XXI, la irrupción de la Web ha modificado el escenario (ahora 2.0) y la interactividad del usuario es ya una realidad sin renunciar por supuesto a las posibilidades que ofrece el consumo lineal del relato.

Palabras clave: Audiovisual; soporte audiovisual; formato audiovisual; interacción; relato lineal ; relato no lineal; hipertexto

\section{The audiovisual tapeless and the collapse of linearity in the story}

\begin{abstract}
The audiovisual sector is inside a deep transformation. In this context, this paper analyses the evolution in the twentieth century, with the emergence and consolidation of the mass media (1.0). Now the narrative limitation and the linear tale is something past. In the late twentieth and early twenty-first century, the emergence of the Web has changed the scenario (now 2.0) and user interactivity is a fact. The challenge is discover how to introduce the benefits without loosing the advantges of the traditional narration.
\end{abstract}

Keywords: Audiovisual; audiovisual storage; audiovisual archives; interaction; linear story; nonlinear story; hypertext

Referencia normalizada:

Arnau Roselló, R. y Galán Cubillo, E. (2013) La disolución del soporte audiovisual y la quiebra de la linealidad en el relato. Historia y Comunicación Social. Vol. 18. No Especial Diciembre. Págs. 359-367.

Sumario: 1. Evolución y transformaciones del sistema audiovisual global. 2. Del dominio del soporte... a su desmaterialización. 3. Consecuencias de la desintegración del soporte audiovisual. 4. El momento actual: de lo lineal a lo no-lineal y viceversa. 5. Conclusiones 


\section{Evolución y transformaciones del sistema audiovisual global}

La costumbre de nuestros antepasados de reunirse al finalizar el día para transmitir la tradición oral de la comunidad pervive aún hoy, aunque la hoguera alrededor de la cual se compartían los relatos hoy ha sido transformada en pantalla y ha pasado de ser el medio a convertirse en el propio mensaje. El reemplazo de la hoguera por la pantalla, como centro del salón hace décadas o la reciente transformación de la televisión analógica por la conectada a Internet en la última década no son, pese a su centralidad, los hitos fundamentales en el cambio experimentado en el sector audiovisual. Los medios de comunicación de masas aparecidos en el siglo XX no concedían al espectador ninguna opción de participar en el relato, el mensaje estaba en manos del emisor. Aunque se incorporaron pequeñas ventanas para suplir esta carencia (el teletexto o las llamadas telefónicas) las posibilidades que ofrecían eran muy limitadas y el discurso tendía inequívocamente a la unidireccionalidad.

Esta ausencia de feedback generaba un efecto desnaturalizador en el proceso comunicativo y motivó que los emisores, y fundamentalmente los espectadores, demandaran soportes o formatos narrativos que permitieran tanto la selección como la interacción con los contenidos seleccionados. Esta aspiración sirvió de aliento al proceso de multiplicación de pantallas desarrollado en las dos últimas décadas. El consumo interactivo y la multiplicación de pantallas son movimientos que han ido de la mano, implicándose mutuamente hasta integrar sus respectivas evoluciones.

Es evidente, pues, que como seres sociales, el consumo de un contenido sin poder ser compartido y comentado con nuestros semejantes es un acto incompleto, insatisfactorio e incluso insensato si lo analizamos en términos antropológicos o evolutivos. Y precisamente, es en este punto donde cobra siginificado el éxito exponencial de Internet y las Redes Sociales como plataformas para el relato audiovisual (Galindo, 2012). La vinculación entre el audiovisual y el sector de las telecomunicaciones ha ofrecido al usuario la posibilidad de hacer compatible un consumo a la carta del relato sin que ello implique una exclusión. Nuestra intención pues, es tratar de despejar algunos interrogantes acerca de este proceso de disolución progresiva de los formatos audiovisuales y su implicación con los cambios que introduce la hegemonía actual del hipertexto como vehículo para generar contenido. La exploración de este terreno particular, de este nuevo soporte digital es el objetivo de este análisis.

\section{Del dominio del soporte... a su desmaterialización.}

Bien es cierto que podemos explicar la historia del soporte audiovisual como una lucha por su dominio, adaptación, abaratamiento... hasta que finalmente conseguido el objetivo lo hemos dejado desaparecer quedándonos hasta el momento huérfanos de un sistema alternativo de registro físico perdurable en el tiempo. Pero retrocedamos primero unos años para recordar como aunque la eclosión de los medios de 
comunicación de masas tiene lugar en el siglo XX, es ya desde el siglo XIX cuando comienzan a configurarse a nivel tecnológico los dos soportes fundamentales que tendrán los nuevos medios en el siglo XX: el soporte fotográfico y el electrónico, que durante el siglo pasado fueron evolucionando en un proceso imparable de convergencia (Amorós, 2010).

Esta permanente relación entre los diferentes soportes y formatos ha generado interacciones entre diferentes lenguajes y medios que han abierto nuevas vías de exploración. Por ejemplo, hoy los productos de ficción más influyentes se estrenan en televisión y tienen un formato serial mientras que en la sala de exhibición cinematográfica asistimos en directo a retransmisiones que hasta ahora estaban reservadas a la televisión. La multiplicación de la diversidad de ventanas y formatos de exhibición ha supuesto un acicate para la hibridación permanente de soportes, medios y discursos que la seña de identidad de la era digital.

Repasando la evolución tecnológica del cine y del vídeo desde un punto de vista estrictamente narrativo, la aparición de la posibilidad técnica para editar la imagen puede considerarse como el hito decisivo. El cine como la herramienta diegética más popular disponía a través de la moviola de la posibilidad de controlar el tiempo del relato desde sus inicios. El proceso de revelado en laboratorio daba también la posibilidad al realizador de controlar la representación espacial, de realizar efectos de superposición, sobreimpresiones etc. El vídeo sin embargo, nació mucho más limitado en sus iniciales posibilidades expresivas. Aunque a partir de la II Guerra Mundial la televisión ya era un medio de comunicación de masas consolidado en EEUU el magnetoscopio y por tanto, la posibilidad de reproducir posteriormente el material capturado por la cámara, no existió hasta 1957.

Desde entonces, la televisión se libera del requisito de simultaneidad entre la producción y la emisión del contenido, viviendo así una segunda gran expansión. La posibilidad de alterar el orden y la duración del material registrado en el caso del vídeo no llegaría hasta 1960 con el sistema Editec. El proceso de control del tiempo se completó en 1982 con la posibilidad de editar con precisión de un cuadro de imagen en el vídeo. La aparición de un magnetoscopio (1" C) que grababa una pista con el código de tiempos facilitó también la tarea. El vídeo por tanto, hace 30 años ya había conseguido el mismo estatus y poder de control temporal que había gozado el cine desde sus inicios. Este control aventuraba un potencial narrativo que faltaba ser completado por la transformación definitiva: el divorcio de la representación icónica de su referente real (Galán, 2009).

El advenimiento del vídeo digital se constituyó en el principal aliado para alcanzar esta conquista. La utilización de cámaras y equipos de edición digitales permitió el uso de equipos informáticos para la edición no lineal y la introducción de efectos en la imagen a través del software que permitía trabajar con la imagen en diferentes capas. La tradicional fase de montaje se transformó en postproducción y la tradicional imagen vinculada a un referente real devino en un lienzo en el en cuya superficie se podía componer una imagen de síntesis. Desde entonces todo es posible, el límite, 
si lo hay, sólo reside en la capacidad de trabajo y en la imaginación del creador (Galán, 2008).

A comienzos de la década pasada la digitalización del entorno audiovisual ya era una realidad constatable en el sector. La posibilidad de postproducir el material audiovisual mejoró la calidad de recepción del espectador y facilitó los procesos de producción y postproducción en un proceso sin precedentes en la historia del medio.

Para algunos autores, el soporte digital permitió la compresión de la información y por tanto era posible comprimir, archivar y recuperar la información (Casero, A; Marzal, J., 2011); para otros, el paso del átomo al bit era ya una realidad (Stevens, 2012) que impulsaba por su parte el próximo cambio: la introducción de los medios audiovisuales y su distribución bajo demanda a través de los diferentes servicios ofrecidos a través de Internet. El cambio de paradigma es de tal envergadura que sus resultados y cristalizaciones son impredecibles en el actual contexto de la sociedad líquida, pero, no obstante, se pueden seguir ciertos rastros.

\section{Consecuencias de la desintegración del soporte audiovisual}

En esta última década, el panorama se presenta plagado de un sinfín de posibilidades de combinación de formatos y medios presidido por el papel preeminente de la construcción hipertextual, dominante en el actual entorno universal y abiertamente participativo (aunque también trazable) de la world wide web. En este contexto es fundamental tener en cuenta que uno de los principales facilitadores de las formas de producción participativas es la proliferación de equipos, dispositivos, herramientas informáticas y plataformas que estimulan la creación independiente y la autoproducción (Roig Telo, 2012: 21), cuyo alcance se potencia a través de Internet.

De ahí que la convivencia de procedimientos y co-presencia de formatos sea un hecho constatable de la era digital, en la que la interacción del usuario introduce quiebras sustanciales en el modelo autor-espectador heredado del periodo analógico. Conceptos como crossmedia, remediación, transmedialidad o narrativas no lineales, remiten precisamente a esta cuestión central de la representación audiovisual contemporánea (Gómez Tarín; Rubio, 2010: 63).

El paso a las memorias en estado sólido, ha sido uno de los más decisivos, pues anticipa de algún modo el advenimiento de la nube como repositorio universal de los contenidos digitales (tanto textos, como imágenes, como hipertextos) en la actualidad. Este tipo de memorias, que habitualmente habían sido destinadas al volcado doméstico de información dada su escasa capacidad de almacenamiento y su limitada velocidad de transferencia, han ido poblando el paisaje tecnológico hasta convertirse en un estándar universal en sustitución de los soportes tradicionales. Su capacidad de albergar cualquier tipo de archivo digital, les convierte en los nuevos soportes hegemónicos, potencialmente receptores de cualquier clase de producto audiovisual. De igual modo, lo que conocemos coloquialmente como la nube, servidores de altas 
prestaciones dedicados a la reproducción de vídeo bajo demanda, se configura como el contenedor perfecto para este tipo de archivo/soporte, garantizando la inmediatez del servicio aunque muchas veces en detrimento de la calidad de la reproducción.

De otro lado, si el modelo blockbuster animó las pasadas décadas y sirvió para afianzar la extensión global de los soportes magnéticos, ahora es el streaming (uno de los exponentes del poder de almacenamiento de la nube) el que ocupa su lugar privilegiado, sirviendo dos de cada tres vídeos de los que se consumen en el planeta a través de la web. La red, como espacio común de todas las pantallas y heredera de la hoguera, se convierte así en una ventana aglutinadora de ventanas, en una dispensadora de historias adaptadas a los nuevos retos expresivos y a la emergencia de tecnologías que sean adaptables a su soporte. Plataformas como Youtube, Vimeo, Wuaki, Filmin, Cineclick, VK, Streamcloud o Voddler han sido las primeras en comprender el valor de esta nueva forma de distribución, de amplio alcance, que implica modificaciones en los modos de acceder a los contenidos audiovisuales por parte de los usuarios y supone, de facto, una profunda transformación en el esquema de distribución y exhibición implementado hasta ahora. La posibilidad de elección del nuevo espect-actor es el primer paso hacia la construcción de universos narrativos con un fuerte grado de interacción, en los ya no operan las mismas fuerzas que en los universos narrativos lineales. Tal y como hemos comentado en otro lugar, sin abandonar las herramientas retóricas heredadas de los medios precedentes, estas nuevas narrativas visuales han propiciado también nuevos usos, particularizando así sus capacidades expresivas y significantes (Arnau, 2013).

\section{El momento actual: de lo lineal a lo no-lineal y viceversa}

Uno de los principios que promueven el advenimiento de esta tendencia general es el desarrollo simultáneo de las narrativas no-lineales, cuyo esquema narrativo de estructura en multipantalla, entendida como posibilidad de interacción y organización hipertextual, supone una fractura brusca de las condiciones narrativas de los productos audiovisuales analógicos que venían siendo consumidos desde buena parte del siglo XX. Esto nos permite aseverar que los medios interactivos han resituado la experiencia audiovisual fuera del contexto tradicional de creación-recepción cinematográfica, ya que desplazan a otro terreno cuestiones tan trascendentales como el uso de las herramientas de producción y distribución, el control de la narración por parte del autor, o el papel generativo del nuevo espectador-interactor (Arnau, 2013).

Hasta el momento teníamos bastante bien identificado dos tipos básicos de consumo audiovisual. El consumo lineal se producía en el salón de casa o en la sala de exhibición cinematográfica, espacio en el que al espectador se le otorgaba una posición cómoda (sofá de casa o butaca en el cine) recibiendo de forma pasiva el contenido, sin posibilidad de diálogo, ni una remota intervención en la diégesis. La comodidad del espacio receptivo parecía invitar y legitimar la pasividad del espectador. En el 
otro lado, teníamos la pantalla del ordenador como espacio de consumo interactivo implementado de forma eficaz a través de la conexión a Internet. La oficina o la mesa de escritorio en casa invitaba, por el contrario, a una actitud activa en la que el usuario ejecutaba acciones y participaba del relato hipertextual que ofrecía la Web.

En el inicio de la segunda década del siglo XXI la tablet (y la nueva generación de teléfonos inteligentes) ha modificado esta dualidad de consumo lineal/no-lineal haciendo compatibles ambas opciones y a su vez, completando a las otras pantallas. La posibilidad de observar una pantalla móvil en cualquier ubicación (normalmente con cierta comodidad) nos da la capacidad de poder pasar de un consumo pasivo a una actitud interactiva de forma natural. La tablet actual ya no dirige el tipo de consumo o de actitud del espectador si no que le ofrece ambas vías que puede ejecutar incluso de forma simultánea si así lo desea. Esta nueva dualidad abre nuevos escenarios de tránsito al relato interactivo. El hipertexto hoy ha acabado con la hegemonía de la linealidad y puede adoptar distintas formas en función de la elección del usuario, y de un elevado número de variables (grado de interacción, complejidad estructural del aplicativo, niveles de narración, etc.) que lo alejan de la función estrictamente referencial y lo sitúan en un terreno más cercano a la hermenéutica. La interpretación frente a la narración y el papel activo del usuario, son condiciones indispensables para el impacto narrativo de los productos hipertextuales.

Por tanto, y para que esta condición sustancial pueda traducirse en retornos tangibles para el productor del contenido es necesario habilitar sistemas de medición que vayan más allá de lo cuantitativo. Si estamos ante un contexto de convivencia e hibridación entre lo lineal y lo no lineal debemos de implementar estrategias que permitan analizar la observación y la participación de la audiencia en los contenidos. Hoy sabemos que más de un tercio de la interacción que se produce por ejemplo en Twitter en España en la franja horaria del prime time televisivo tiene como objeto fundamental el comentario sobre la programación televisiva (www.tuitele.tv). La aparición de plataformas como Tuitele que analiza y mide este tipo de interacciones ofreciendo datos cualitativos sobre el target y el nivel de implicación de los internautas en los contenidos se adivina como una herramienta decisiva para contrarrestar la tiranía de la medición cuantitativa de las audiencias a la que los medios audiovisuales han estado hasta ahora sometidos.

Esta transformación que aparentemente parece tener sólo repercusiones en el terreno socio-económico también está afectando a los contenidos. Ya no es suficiente la apelación vacua a la pulsión escópica más básica del espectador porque los anunciantes cada vez más contrastan los datos cuantitativos de audiencia con la actividad y participación de los usuarios en los contenidos. Aunque cierto es que el perfil de usuario de estos medios sociales no es representativo de toda la población, cada vez más se van haciendo más difusos los perfiles sociales, geográficos y de edad de los usuarios de estos medios y por tanto, se va incrementando la representatividad y relevancia de los mismos a una gran velocidad. 


\section{Conclusiones}

La Web ha alentado hibridaciones entre medios y formatos como el podcast, el documental web o los repositorios de vídeo fruto de la convivencia en red de diferentes lenguajes. Estas transformaciones han socavado los cimientos de la industria audiovisual y han modificado la cadena de generación de valor.

Sin embargo, es necesario primero identificar los principales usos del vídeo en Internet para poder así describir las causas de esta revolución. La Web es una ventana más a través de la cual se puede producir y emitir vídeo como contenido y en nada (más bien al contrario) perjudica este tipo de ventanas al negocio audiovisual. Hay otro uso del vídeo, en este caso como complemento de una web o de un blog, es decir como un material de apoyo para el discurso hipertextual. En tanto que el hipertexto se utilice como tal, es decir, remitiendo y referenciando las fuentes propietarias del contenido, este tipo de uso como complemento actúa como efecto multiplicador del valor del contenido y ofrece además una ventana de acceso adicional para el productor audiovisual.

No obstante, tenemos un último uso del vídeo por Internet, que se caracteriza por su carácter "furtivo". Nos referimos a páginas web que canibalizan la señal de otras cadenas de televisión sin ningún tipo de contraprestación económica. En esta categoría tienen una importancia fundamental también los repositorios de vídeo que alojan y distribuyen material audiovisual del cual no tienen derechos. Esta última categoría (y en ningún caso las anteriormente mencionadas) es claramente la que está lastrando y ralentizando el proceso de construcción y consolidación del nuevo escenario digital. Estamos en un contexto donde aunque el futuro sea el contenido, es decir, seguir contando buenas historias y seguir contándolas bien, el negocio es el software, las aplicaciones, las plataformas que sirven y distribuyen esos contenidos sin en muchos casos, repercutir ninguna parte de sus beneficios en los creadores.

El nuevo modelo digital aunque ya apunta algunas vías de negocio (aplicaciones móviles de pago, tarifas planas de consumo de productos, pago por visión, crowdfunding etc.), no las ha consolidado de forma suficiente y esto está frenando la carrera de muchos creadores que no ven ahora en la industria audiovisual una ventana sostenible en la que desarrollar sus proyectos. Es un movimiento de tal alcance que sus procesos son, por naturaleza, lentos.

El reto en la actualidad se concentra en hacer compatible el consumo del relato lineal clásico (que sigue gozando de un notable éxito entre le público, incluso el más joven) con el empleo de medios interactivos sin que esta convivencia implique una pérdida del ritmo narrativo o de las cualidades expresivas del producto. Para ello es necesario contar con el talento de creadores, desarrolladores y experimentadores gráficos, que desplieguen sus potenciales en un modelo de negocio digital en red consolidado, donde la presencia de un sector equilibrado supone una mejora de facto para cada uno de los proyectos. Dada la escasez de ejemplos, habrá que afinar la mirada y prestar atención a estas nuevas convivencias visuales. 


\section{Referencias bibliográficas}

Libro, un autor

GALÁN, E. (2008) Televisión en virtual. Madrid: IORTV

Libro, varios autores

CASERO RIPOLLÉS, A. y MARZAL FELICI, J. (eds.) (2011): Periodismo en televisión: nuevos horizontes, nuevas tendencias. Zamora y Sevilla: Comunicación Social Ediciones y Publicaciones.

Capítulo de libro

AMORÓS PONS, Anna y FONTÁN MAQUEIRA, Ma Olga (2010): "Soportes y formatos en la nueva producción audiovisual", En: ACTAS DEL II CONGRESO INTERNACIONAL AE-IC

ARNAU ROSELLÓ, Roberto (2013): “Derivas contemporáneas del cine de lo real: El webdocumental como espacio hipertextual participativo", en: CAMILO, E.; GÓMEZ TARÍN, F. J. (Coords.) (2013), Saberes para compartir - Partilhar Saberes - Estudios de comunicación: Narrativas mínimas en nuevos discursos audiovisuales. Metodología y análisis aplicado, Covilhà, Universidade da Beira Interior (Portugal), 2013 [Edición bilingüe]. En prensa.

CABRERA, M. A. (2010): “Análisis del impacto de la evolución tenológica en los cibermedios" En el contexto de la convergencia digital", en: ACTAS DEL II CONGRESO INTERNACIONAL AE-IC MÁLAGA 2010 "Comunicación y desarrollo en la era digital”. Málaga: Servicio de Publicaciones de la UMA.

Revistas científico-profesionales de primer y segundo nivel

GALÁN, E. (2010) "La realidad virtual en televisión: el paso del átomo al bit” En Revista Ámbitos: Revista Internacional de Comunicación. nº19, Año 2010 pp. 9-24. Sevilla: Universidad de Sevilla

GALÁN, E. (2011) "El trabajo del presentador de televisión en un escenario virtual" en Revista Latina de Comunicación Social” n64 pp. 143-150. La Laguna (Tenerife): Universidad de la Laguna.

GALINDO, Fernando (2012): "Contenidos audiovisuales para Smartphones. Análisis de usabilidad y adecuación al medio", en: Enlace. Revista Venezolana de Información Tecnología y conocimiento. Vol.3, Año 9, pp.63-82

GOMEZ TARÍN, Fco. Javier y RUBIO ALCOVER, Agustín (2010): “Ojos que no ven: algunas cuestiones en torno al cine contemporáneo" en: Enlace. Revista Venezolana de Información Tecnología y conocimiento. Vol.1, Año 7, pp.61-78.

ROIG TELO, Antoni (2012): "Cine en abierto: formas y estrategias de producción basadas en la participación”, en: L’Atalante. Revista de estudios cinematográficos, Vol. 13, 2012, pp. 20-27.

STEVENS, Martijn (2012): “Conformarse con la nada: la materialización de lo digital”, en: Artnodes. Revista de Arte, Ciencia y Tecnología, nº12, UOC. 
* El presente estudio ha sido financiado con la ayuda del Proyecto de Investigación de la convocatoria Universitat Jaume I-Bancaja, con el título "Análisis de los flujos de transferencia de conocimiento entre los sistemas educativos superiores y la industria del videojuego", código 11I301.01/1, para el periodo 2012-14, bajo la dirección del Dr. Javier Marzal Felici. 